\title{
Inhibition of Bax protects neuronal cells from oligomeric $A \beta$ neurotoxicity
}

\author{
W Kudo', H-P Lee ${ }^{1}$, MA Smith ${ }^{1}$, X Zhü ${ }^{1,2}$, S Matsuyama ${ }^{\star, 1,3}$ and H-g Lee, ${ }^{*, 1,2}$
}

\begin{abstract}
Although oligomeric $\beta$-amyloid (A $\beta$ ) has been suggested to have an important role in Alzheimer disease (AD), the mechanism(s) of how $A \beta$ induces neuronal cell death has not been fully identified. The balance of pro- and anti-apoptotic Bcl-2 family proteins (e.g., Bcl-2 and Bcl-w versus Bad, Bim and Bax) has been known to have a role in neuronal cell death and, importantly, expression levels of these proteins are reportedly altered in the vulnerable neurons in AD. However, the roles of apoptotic proteins in oligomeric $A \beta$-induced cell death remain unclear in vivo or in more physiologically relevant models. In addition, no study to date has examined whether Bax is required for the toxicity of oligomeric $A \beta$. Here, we found that treatment with oligomeric A $\beta$ increased Bim levels but decreased Bcl-2 levels, leading to the activation of Bax and neuronal cell death in hippocampal slice culture and in vivo. Furthermore, the inhibition of Bax activity either by Bax-inhibiting peptide or bax gene knockout significantly prevented oligomeric $A \beta$-induced neuronal cell death. These findings are first to demonstrate that Bax has an essential role in oligomeric $A \beta$-induced neuronal cell death, and that the targeting of Bax may be a therapeutic approach for AD.
\end{abstract}

Cell Death and Disease (2012) 3, e309; doi:10.1038/cddis.2012.43; published online 17 May 2012

Subject Category: Neuroscience

Alzheimer disease (AD) is the most common neurodegenerative disorder, and $\beta$-amyloid $(\mathrm{A} \beta)$ has been suggested to have a critical role in the pathogenesis of $A D$. It has been shown that oligomeric $A \beta$ is a main $A \beta$ species inducing neurodegeneration in $A D$, yet the molecular mechanism(s) of its neurotoxicity remains elusive. ${ }^{1}$ At present, it is reported that oligomeric $\mathrm{A} \beta$ induces apoptotic neuronal death in the rat and mouse neurons in vitro and in vivo. ${ }^{2,3}$

Previous studies found that expression levels of $\mathrm{Bcl}-2$ family proteins, such as Bax, Bak, Bad, Bcl-2, Bim, Bcl-w and $\mathrm{Bcl}-\mathrm{x}$ are altered in the vulnerable neurons in $\mathrm{AD} .{ }^{4} \mathrm{Bcl}-2$ family is structurally defined by the presence of up to four conserved 'BCL-2 homology' (BH) domains. The family proteins are the key regulators of evolutionally conserved pathway of apoptosis. ${ }^{5,6}$ Bax and Bak belong to the multi-BH domains pro-apoptotic subfamily, which promotes apoptosis by translocating into the mitochondrial membrane and facilitating cytochrome $\mathrm{c}$ release whereas $\mathrm{Bcl}-2$ and $\mathrm{Bcl}-\mathrm{XL}$ belong to the prosurvival subfamily, which prevents apoptotic death in multiple cell types including neuron. ${ }^{7}$ It is hypothesized that the BH3-only proteins, such as Bim, Bid, Puma, Noxa and Bad induce the activation of Bax and Bak, either directly or indirectly by inactivating the prosurvival $\mathrm{Bcl}-2$ proteins. In the presence of apoptotic stimuli, Bax is known to change its conformation. Specifically, as an early step of Bax activation, the $\mathrm{N}$-terminus exposure is considered a prerequisite for membrane insertion of Bax at mitochondria and multimerization of Bax. ${ }^{8,9}$ Ku70, a DNA repair factor, can prevent the conformational change by binding with Bax in the cytosol, which leads to the inhibition of Bax-mediated cell death. ${ }^{10}$ Previously, a cell permeable Bax-inhibiting peptide (BIP), designed to induce the Bax-binding domain of Ku70, was found to rescue cells from Bax-mediated cell death. ${ }^{10-12}$

Notably, overexpression of anti-apoptotic proteins, Bcl-w, or genetic ablation of a proapoptotic effecter, Bim, significantly protected neurons against fibrillar $\mathrm{A} \beta$-induced apoptosis in neuroblastoma cell lines and primary neuron culture. ${ }^{13,14}$ Giovanni et al. ${ }^{15}$ also reported that fibrillar $\mathrm{A} \beta$-induced cell death is dependent on Bax in primary neuron culture. However, these results have never been confirmed in vivo or in a more physiologically relevant model, and all the previous studies examined the toxicity of fibrillar $\mathrm{A} \beta$, not oligomeric $\mathrm{A} \beta$. Therefore, to advance our understanding of the involvement of $\mathrm{Bcl}-2$ protein family as the major mechanism of oligomeric $\mathrm{A} \beta$-induced neuronal cell death, in this study, we examined the effect of oligomeric $\mathrm{A} \beta$ on the regulation of $\mathrm{Bcl}-2 / \mathrm{Bim} / \mathrm{Bax}$ and its functional importance in neuronal cell death in the organotypic hippocampal culture and mouse model for $\mathrm{A} \beta$ toxicity.

\section{Results}

Oligomeric $\mathbf{A} \boldsymbol{\beta}$ induces $\mathrm{Bim}$ upregulation and $\mathrm{Bcl}-2$ downregulation in hippocampal slice culture. To characterize oligomeric $\mathrm{A} \beta$ in this study, we synthesized $\mathrm{A} \beta$

\footnotetext{
${ }^{1}$ Department of Pathology, Case Western Reserve University School of Medicine, Cleveland, OH, USA; ${ }^{2}$ Department of Neurology, Case Western Reserve University School of Medicine, Cleveland, OH, USA and ${ }^{3}$ Departments of Medicine and Pharmacology, Case Western Reserve University School of Medicine, Cleveland, OH, USA *Corresponding authors: H-g Lee or S Matsuyama, Department of Pathology, Case Western Reserve University, 2103 Cornell Road, Cleveland, OH 44106, USA. Tel: 216368 6887; Fax: 216368 8964; E-mail: hyoung-gon.lee@ case.edu (H-gL) or shigemi.matsuyama@case.edu (SM)

Keywords: Alzheimer disease; neuronal cell death; Bax; Bim; Bcl-2; $\beta$-amyloid

Abbreviations: $\mathrm{A} \beta, \beta$-amyloid; $\mathrm{AD}$, Alzheimer disease; $\mathrm{BH}, \mathrm{BCL}-2$ homology; BIP, Bax-inhibiting peptide; PI, propidium iodide; TUNEL, terminal dUTP nick-end labeling; FITC, fluorescein isothiocyanate; JNK, c-Jun N-terminal kinase; cdk4, cyclin-dependent kinase 4

Received 6.1.12; revised 7.3.12; accepted 26.3.12; Edited by D Bano
} 
peptide, and then denatured the peptide and allowed oligomers to form, as described for $\mathrm{A} \beta$-derived diffusible ligands. ${ }^{1}$ Consistent with previous findings for oligomeric $\mathrm{A} \beta,{ }^{1,16}$ our oligomeric $\mathrm{A} \beta$ preparations contain spherical particles visible by negative staining with transmission electron microscopy, and western blots show that the preparations contain various size of oligomeric proteins (Figure 1).

Time-dependent changes of the levels of Bax, Bcl-2 and Bim were examined in oligomeric $\mathrm{A} \beta$-treated brain slices. Oligomeric $A \beta$ increased the expression of Bim but decreased the level of Bcl-2 (Figure 2a). However, the level of Bax was not affected by oligomeric $\mathrm{A} \beta$ (Figure $2 \mathrm{a}$ ). As the $\mathrm{N}$-terminus exposure is an early step of Bax activation that occurs in the cytosol, we analyzed this conformational change of Bax with a monoclonal antibody (6A7) recognizing the epitope in the $\mathrm{N}$-terminus of $\mathrm{Bax} .{ }^{9}$ Although the level of Bax expression was not affected by oligomeric $A \beta$, the number of $6 A 7$-positive cells were significantly increased in oligomeric $A \beta$ treated slice cultures (Figure $2 \mathrm{~b}$ ), suggesting that oligomeric $A \beta$ induces Bax activation.

\begin{abstract}
Ablation of Bax reduces oligomeric $A \beta$-induced neuronal cell death in hippocampal slice culture. To further determine the functional role of Bax in oligomeric $\mathrm{A} \beta$ induced neuronal cell death, hippocampal slice culture prepared from wild-type and $b_{a x}{ }^{-1-}$ mice (Figures $3 a$ and b) were used. Slices were treated with oligomeric $\mathrm{A} \beta$ in the presence of propidium iodide $(\mathrm{PI})$, which penetrates cell membranes of dead or dying cells, and is widely used for evaluation of cell death. Although $\mathrm{A} \beta_{42-1}$ peptide, a reverse sequence of $\mathrm{A} \beta_{1-42}$, had no effect on PI uptake, the number of $\mathrm{Pl}$-positive cells was significantly increased in oligomeric $\mathrm{A} \beta$-treated slices after $48 \mathrm{~h}$ of the treatment, indicating that
\end{abstract}
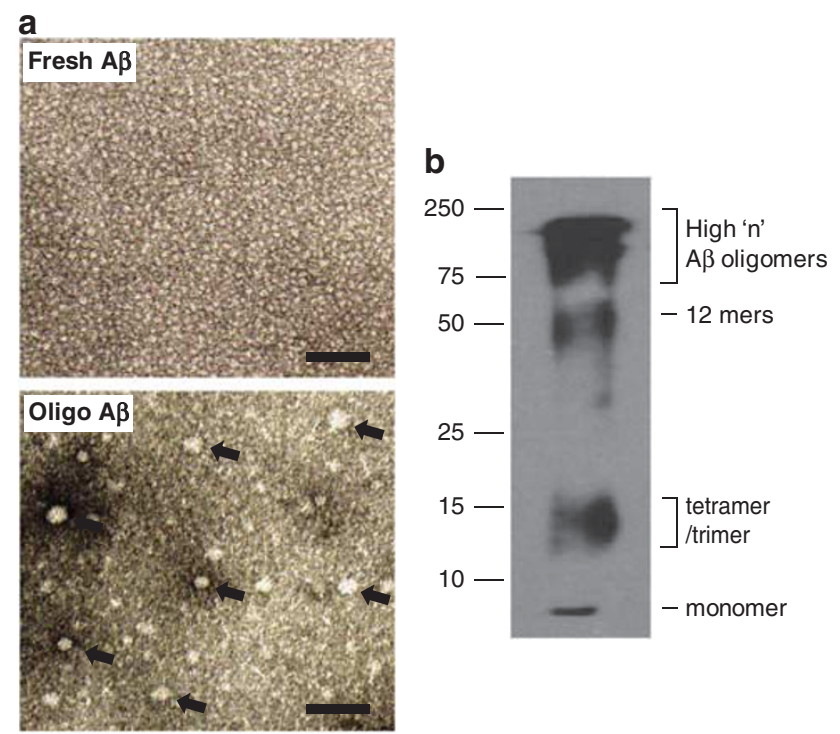

Figure 1 Physicochemical and morphological features of the synthetic $A \beta_{1-42}$. (a) Electron micrograph shows the typical pattern of oligomer formation of $A \beta$. The arrows indicate oligomers in the lower panel. Scale bar, $100 \mathrm{~nm}$. (b) Synthetic $\mathrm{A} \beta_{1-42}$ was subjected to SDS-polyacrylamide gel and detected by western blotting with $6 \mathrm{E} 10$ antibody. Molecular weight markers in $\mathrm{kDa}$ are at left oligomeric $\mathrm{A} \beta$ induces neuronal cell death in the hippocampal slice culture. However, the neuronal cell death induced by oligomeric $\mathrm{A} \beta$ was dramatically reduced in the slice culture from $b^{-1-}$ mice (Figure $3 c$ ). Nissl staining analysis further confirmed neuronal cell death by oligomeric $A \beta$ in wild-type (WT) mouse slice culture but not in $b^{-1-}$ mouse slice culture (Figure $3 d$ ). These results indicate that Bax is a critical mediator for the neurotoxicity induced by oligomeric $\mathrm{A} \beta$.

Intrahippocampal injection of oligomeric $A \beta$ increases Bim expression and active forms of Bax. To further examine the involvement of pro-apoptotic proteins in oligomeric $\mathrm{A} \beta$-induced cell death, we determined the change of the levels of Bim and the active form of Bax in vivo. We injected oligomeric $A \beta$ into the hippocampus and assessed its neurotoxicity. $A \beta_{42-1}$ was used as a control. Oligomeric $A \beta$ injection into the WT mouse hippocampus induced neuronal cell death in 20 days after injection (Figure 4a). The number of terminal dUTP nick-end labeling (TUNEL)-positive neurons was significantly increased by $A \beta$ injection (Figure $4 b$ ). To see the involvement of Bim and Bax, we measured the level of Bim and active form of Bax, and found that the level of Bim was dramatically increased as early as 10 days after oligomeric $\mathrm{A} \beta$ injection (Figure $4 \mathrm{c}$ ). The number of neurons containing the active form of Bax recognized by $6 \mathrm{~A} 7$ antibody was also dramatically increased by $A \beta$ injection (Figure $4 d$ ). These data further support that both Bim and Bax have roles in oligomeric $\mathrm{A} \beta$-induced neuronal cell death.

BIP suppresses neuronal cell death and Bax activation induced by oligomeric $\mathbf{A} \boldsymbol{\beta}$ in hippocampal slice culture. In this study, in addition to utilizing Bax knockout (KO) mice, we utilized BIP to examine the role of Bax in oligomeric $\mathrm{A} \beta$-induced neurotoxicity. BIP used in this study consists of five amino acids, VPTLK, a sequence that is known to inhibit Bax activation. ${ }^{10,11,17}$ A mutated (scrambled) peptide, KLVPT, which does not bind Bax but has the same cell permeability, was used as a negative control. Both peptides were tagged with fluorescein isothiocyanate (FITC) so that intracellular delivery can be tracked by FITC signal. We first treated hippocampal slices with each peptide and analyzed green fluorescence to confirm their cell permeability, and confirmed that BIP and the control peptide equally penetrated neuronal cells after 24-h treatment (Figure 5a). To determine whether BIP is able to suppress oligomeric $A \beta$ induced neuronal cell death in slice culture, either BIP or control peptide were co-applied with oligomeric A $\beta$. After 24$\mathrm{h}$ treatment of oligomeric $\mathrm{A} \beta$ and the peptide, the treatment of BIP significantly prevented PI uptake, whereas the control peptide did not affect the level of PI uptake (Figure 5b), suggesting BIP specifically blocks neuronal cell death induced by oligomeric $\mathrm{A} \beta$. Consistent with the $\mathrm{PI}$ uptake results, both Nissl staining and caspase- 3 immunoblot analyses also showed that BIP significantly suppressed oligomeric $\mathrm{A} \beta$-induced neuronal loss and caspase- 3 activation, but control peptide failed to prevent neuronal cell death (Figures $5 c$ and $d$ ). We also found that the treatment of BIP suppresses oligomeric $A \beta$-induced conformational change of Bax (Figure 6). These results further support the hypothesis 


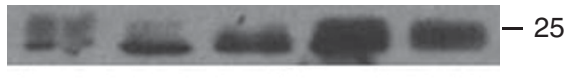

Bcl-2

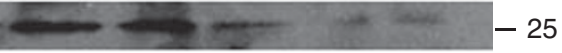

$\mathrm{Bax}$

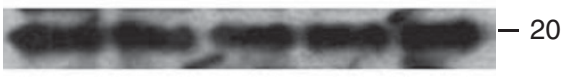

Actin
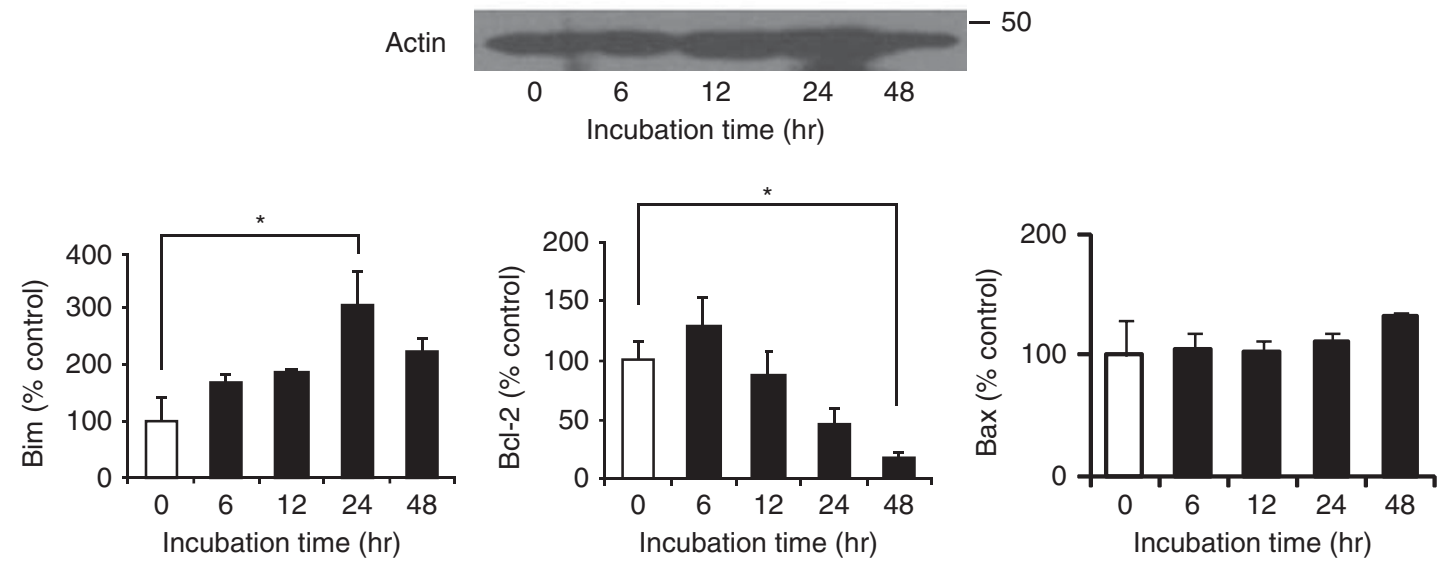

b

$6 \mathrm{~A} 7$

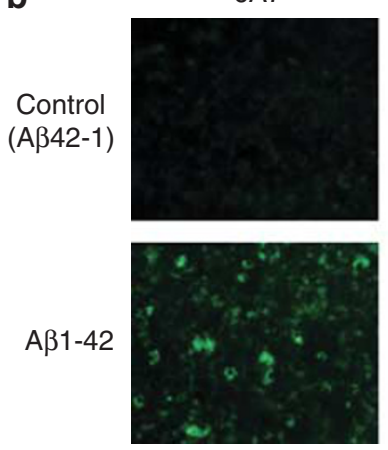

DAPI

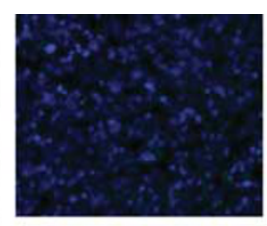

6A7+DAPI
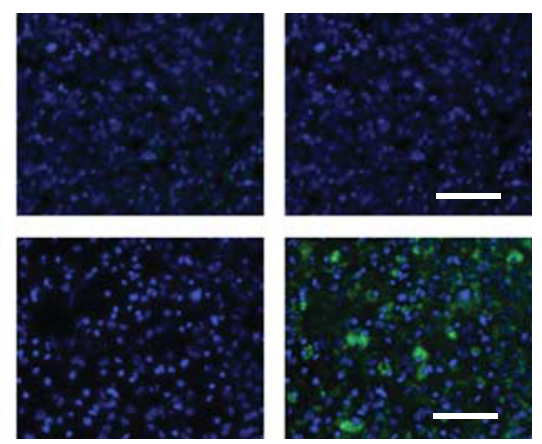

Figure 2 Oligomeric $\mathrm{A} \beta$ differentially regulates $\mathrm{Bim}, \mathrm{Bcl}-2$ and $\mathrm{Bax}$ in the hippocampal slice culture. (a) Representative western blots showed oligomeric $\mathrm{A} \beta$ induced upregulation of Bim and downregulation of Bcl-2 in a time-dependent manner. Bax levels were not changed by oligomeric $\mathrm{A} \beta$ treatment. Actin was used as internal loading control. The values of each band were normalized to that of actin and shown as a relative value of each group compared with the non-treatment slices. The indicated comparisons are significant at ${ }^{*} P<0.05, n=4$. (b) Immunocytochemistry analysis demonstrated the increased number of positive cells stained with $6 \mathrm{~A} 7$ antibody, which specifically detect the active form of $\mathrm{Bax}, 24 \mathrm{~h}$ after oligomeric $\mathrm{A} \beta$ treatment in hippocampal slice cultures. Conversely, control peptide $\left(A \beta_{42-1}\right)$ did not induce the active form of Bax (green: 6A7, blue: DAPI). Scale bar, $100 \mu \mathrm{m}$

that the activation of Bax by oligomeric $A \beta$ is an essential mechanism of oligomeric $\mathrm{A} \beta$-induced neuronal cell death.

\section{Discussion}

In this study, we demonstrate that oligomeric $\mathrm{A} \beta$ altered the expression levels of $\mathrm{Bcl}-2$, Bim and Bax, and that the genetic or pharmacological ablation of Bax activity suppresses oligomeric $\mathrm{A} \beta$-mediated neurotoxicity in both ex vivo and in vivo. These results clearly indicate that Bax has an essential role in the induction of neuronal cell death caused by oligomeric $\mathrm{A} \beta$.

In healthy cells, Bax is located in the cytosol or loosely associated to mitochondria and endoplasmic reticulum. ${ }^{18} \mathrm{Bax}$ translocation to the mitochondria, which occurs in cells with apoptotic stresses, is thought to lead to mitochondrial dysfunction and release of cytochrome $\mathrm{c}$ and subsequent apoptosis. ${ }^{19}$ Before its translocation to mitochondria, Bax changes its conformation that exposes the $\mathrm{N}$-terminal residues. $^{20}$ This conformational change is believed to be necessary for membrane insertion of Bax at mitochondria and multimerization of $\mathrm{Bax}^{21}$ The present study demonstrates that oligomeric $\mathrm{A} \beta$ induced the $\mathrm{N}$-terminal exposure of Bax in neurons and that the inhibition of this event by BIP rescues neurons from oligomeric A $\beta$ 's neurotoxicity, suggesting the activation of Bax by its conformational change is a key element of oligomeric $\mathrm{A} \beta$-induced neurotoxicity.

Although the molecular mechanism(s) of Bax activation has not been clearly defined, multiple pro-apoptotic proteins (e.g., Bim) and anti-apoptotic proteins (e.g., Bcl-2) are known to regulate the activation of Bax thorough heterodimerization. ${ }^{22}$ In fact, consistent with the previous findings, our current data 
a

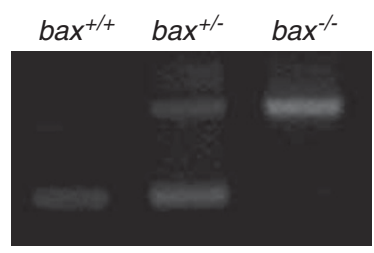

b

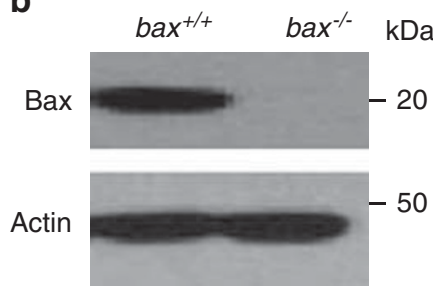

C Control

(Aß42-1)
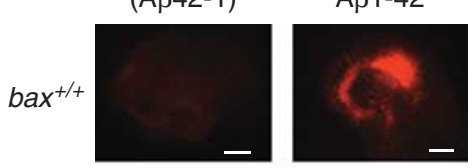

$b^{-1-}$
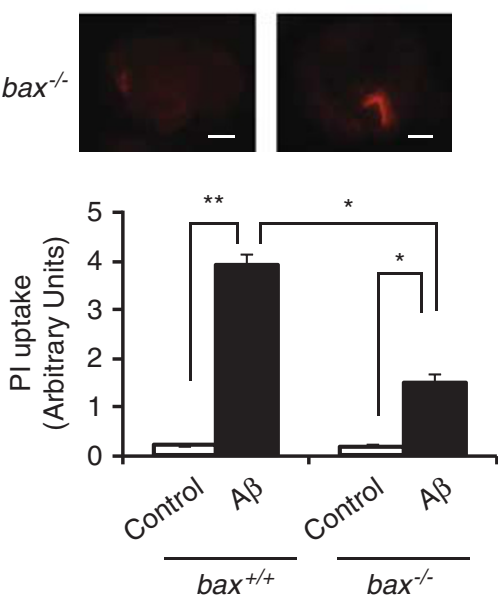

d

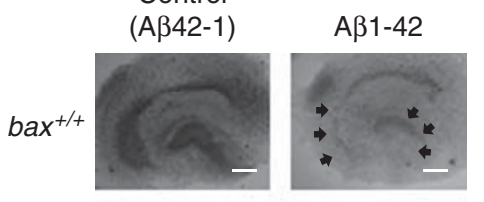

bax $^{-1-}+-$

Figure $3 \mathrm{bax}^{-1-}$ neurons are resistant to oligomeric A $\beta$ neurotoxicity. (a) DNA was extracted from bax ${ }^{+/+}$and bax ${ }^{-1-}$ mice, and each genotype was identified by PCR with the primer sets specifically detecting each genotype as described in the previous study. bax ${ }^{+1+}$ yields a 304-bp PCR product and bax ${ }^{-1-}$ yields a 507-bp PCR product. (b) Total protein $(20 \mu \mathrm{g})$ from whole brain was analyzed by immunoblot with anti-Bax antibody. Immunoblot analysis showed Bax in bax ${ }^{+/+}$mouse samples at the expected molecular weight of $21 \mathrm{kDa}$, and no expression of Bax in bax $^{-1}$ samples. (c) Hippocampal slice culture were treated with oligomeric $A \beta(500 \mathrm{nM})$ in the presence of $\mathrm{PI}$ (red) for $48 \mathrm{~h}$. Representative data showed oligomeric A $\beta$-induced PI uptake was significantly reduced in the slice cultures from bax ${ }^{-1-}$ mice compared with bax ${ }^{+1+}$ mice. The Pl uptake was quantitatively analyzed $(n=5)$. Control $\mathrm{A} \beta_{42-1}$ peptide had no effect on Pl uptake. Scale bar, $500 \mu \mathrm{m}$. ${ }^{*} P<0.05$, ${ }^{\star \star} P<0.01$. (d) Neuronal cell loss by oligomeric A $\beta$ (arrows) was significantly reduced in the hippocampal slice cultures from bax ${ }^{-1-}$ mice. Scale bar, $500 \mu \mathrm{m}$

a Control

(A $\beta 42-1)$

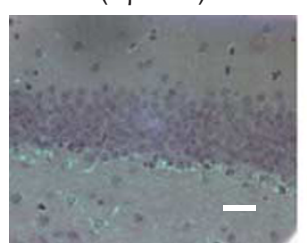

b
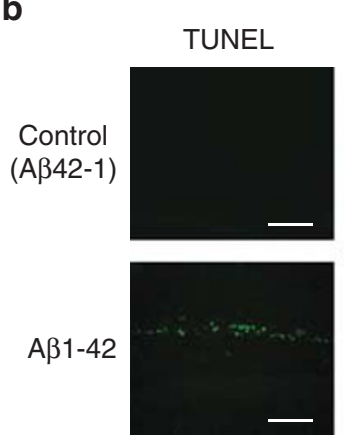

A $\beta 1-42$

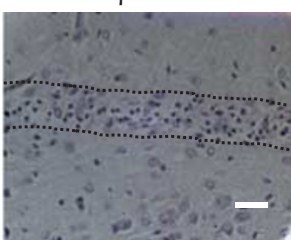

TUNEL

+ DAPI
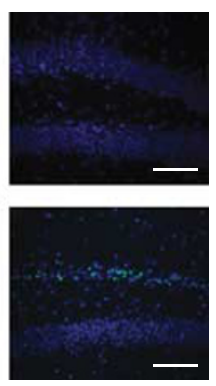

C

Bim

Control

(Aß42-1)
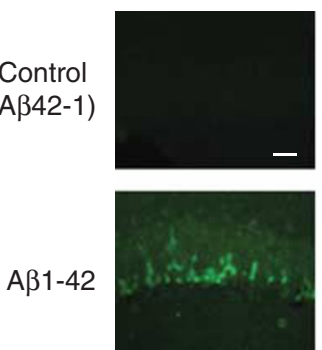

d

Control

(Aß42-1)

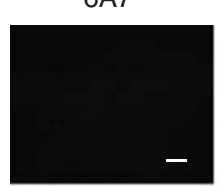

A $\beta 1-42$

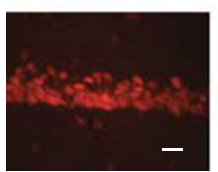

DAPI
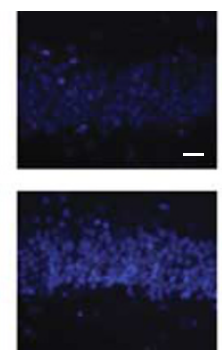

DAPI
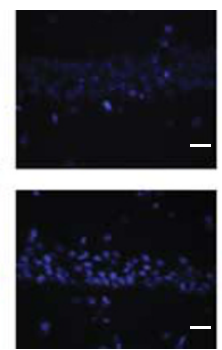

Merge
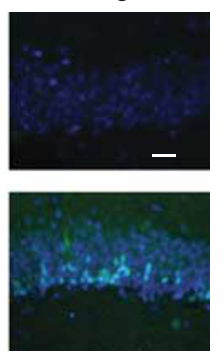

Merge
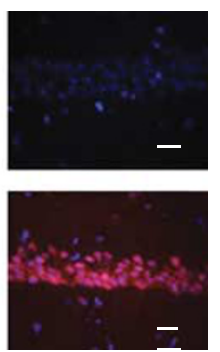

Figure 4 Intrahippocampal injection of oligomeric A $\beta$ upregulates Bim and activates Bax. C57BL/6J mice were killed and the levels of Bim and active Bax were analyzed at 10 or 20 days after oligomeric $A \beta$ injection. (a) At 20 days after oligomeric $A \beta$ injection, neuronal cell loss in hippocampus was evident in $A \beta$ injected mice in $H \& E$ staining, but not in control peptide-injected mice. The region of neuronal cell loss is indicated by dotted lines. Scale bar, $100 \mu \mathrm{m}$. (b) The number of TUNEL-positive cells in hippocampus was dramatically increased after oligomeric A $\beta$ injection whereas virtually no TUNEL-positive cell (green) was detected in control peptide-injected hippocampus tissues. Blue: DAPI. Scale bar, $200 \mu \mathrm{m}$. (c) Immunoreactivity for Bim (green) was increased in hippocampus at 10 days after the oligomeric A $\beta$ injection. Scale bar, $100 \mu \mathrm{m}$. (d) The number of active Bax-positive cells detected by $6 \mathrm{~A} 7$ antibody (red) was dramatically increased at 10 days after the oligomeric A $\beta$ injection. Scale bar, $100 \mu \mathrm{m}$ compared with control peptide-injected mice 
a

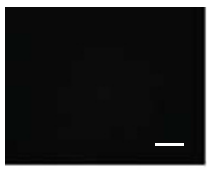

No treatment

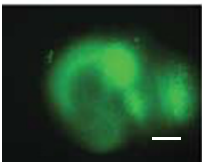

KLPVT

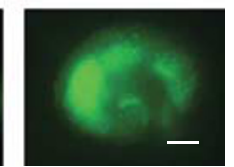

VPTLK

b

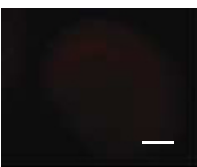

Control

$(\mathrm{A} \beta 42-1)$

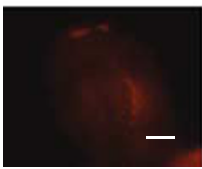

A $\beta 1-42$

+VPTLK

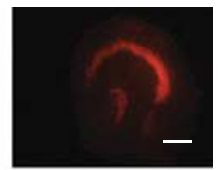

$A \beta 1-42$

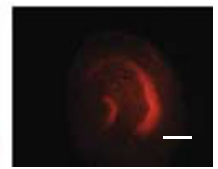

A $31-42$

+KLPVT
C

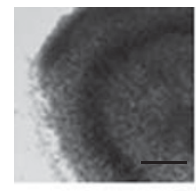

Control

(Aß42-1)

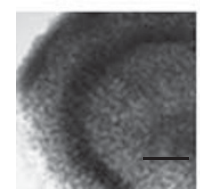

A $31-42$

+VPTLK

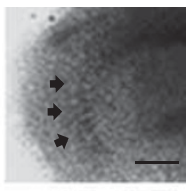

$A \beta 1-42$

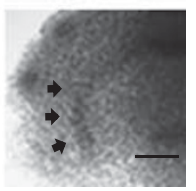

A $\beta 1-42$

+KLPVT d

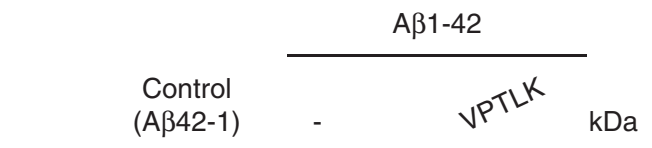

Cleaved

Casp-3

Actin

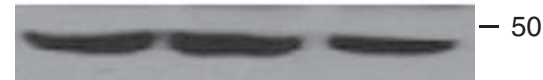

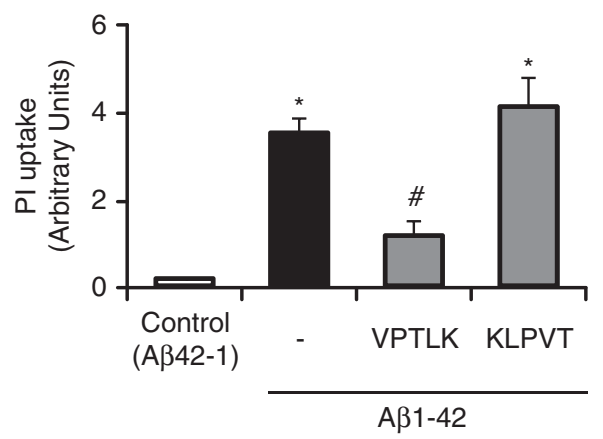

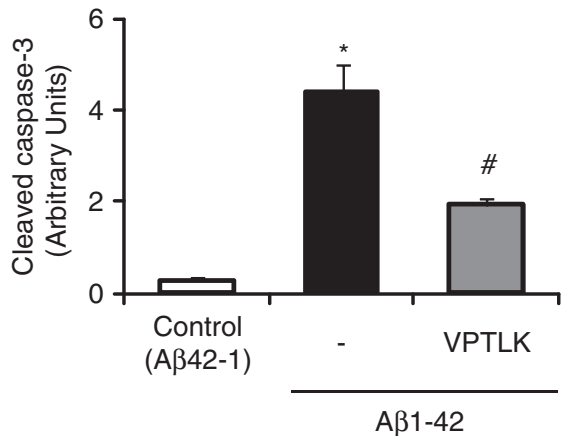

Figure 5 Bax-inhibiting peptide (BIP) suppresses neuronal cell death induced by oligomeric A $\beta$. Either BIP (VPTLK) or control peptide (KLPVT) was added to hippocampal slice cultures at the same time with oligomeric $\mathrm{A} \beta$ to examine its neuroprotective effect. (a) Cell permeability of both peptides was confirmed by green fluorescence in hippocampal slice cultures. Strong green fluorescence of both BIP- and negative-control peptide was found at $24 \mathrm{~h}$ after the peptide treatment, indicating both peptides are penetrated to neurons. (b) The intensity of $\mathrm{PI}$ in slices treated with oligomeric $\mathrm{A} \beta$ for $48 \mathrm{~h}$ was quantified as a marker of cell death. BIP significantly prevented oligomeric $\mathrm{A} \beta$-induced PI uptake $(n=5)$. Scale bar, $500 \mu \mathrm{m}$. ${ }^{*} P<0.01$ versus control ${ }^{\#} P<0.05$ versus $\mathrm{A} \beta$ only $(-)$. A $\beta_{42-1}$ peptide was used as a control. (c) Nissl staining demonstrated that the treatment of BIP significantly prevented neuronal cell loss induced by oligomeric $A \beta$. Arrows indicate the region of neuronal cell loss. (d) BIP suppressed the activation of caspase-3 (cleaved caspase-3) induced by oligomeric $\mathrm{A} \beta(n=4)$. ${ }^{*} P<0.01$ versus control, ${ }^{\#} P<0.05$ versus A $\beta$ only ( - )

demonstrate that the level of Bim is significantly upregulated after oligomeric $\mathrm{A} \beta$ treatment, whereas anti-apoptotic protein $\mathrm{Bcl}-2$ is downregulated, suggesting that oligomeric $\mathrm{A} \beta$ induces neuronal cell death through the alteration of the balance of Bcl-2 family proteins and consequent activation of Bax. Unlike most 'BH3-only' proteins, Bim can interact with all pro-survival $\mathrm{Bcl}-2$ proteins with high affinity, and is one of the few BH3-only proteins that can directly activate Bax. ${ }^{23}$ For instance, several in vitro data suggested that the direct physical interaction between Bim and Bax can drive Bax activation. ${ }^{24,25}$ Importantly, the ablation of Bim suppresses $\mathrm{A} \beta$-induced cell death in primary neurons, ${ }^{13}$ and overexpression of anti-apoptotic proteins (Bcl-w) significantly protected neurons against $A \beta$-induced apoptosis. ${ }^{14}$ Previous reports suggested that overexpression of Bim in cultured neurons induces a rapid apoptotic death ${ }^{26}$ and Bim is highly expressed in $\mathrm{AD}$ neurons. ${ }^{13} \mathrm{Bim}$ is also known to induce Bax activation directly or indirectly. ${ }^{27}$ Collectively, these data strongly 


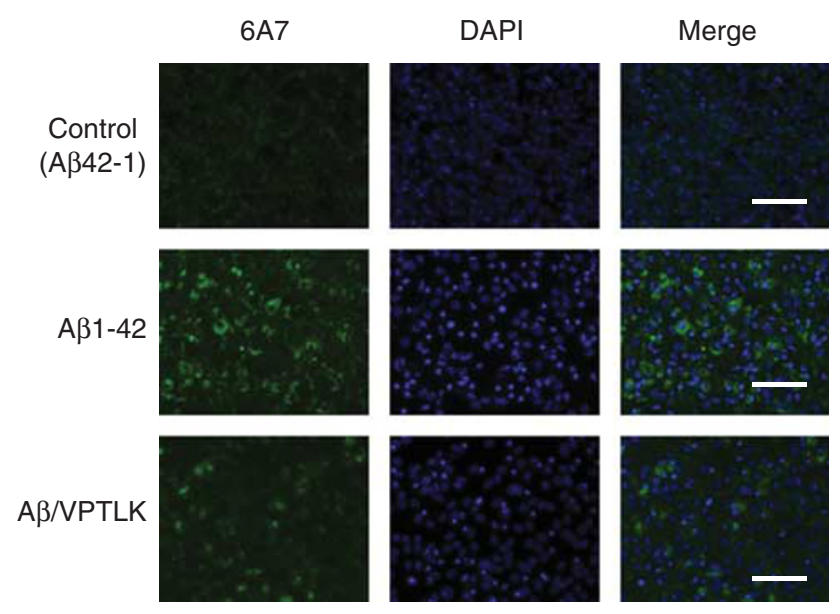

Figure 6 BIP prevents the conformational change of Bax induced by oligomeric $A \beta$. BIP (VPTLK) was treated to hippocampal slice cultures with oligomeric $A \beta$ for $48 \mathrm{~h}$. $A \beta_{42-1}$ was used as a control. The slices were stained with $6 A 7$ antibody for detecting active conformational change of Bax. In the BIP-treated slices, the number and intensity of 6A7-positive signal (green) was significantly decreased compared with the slices treated with $\mathrm{A} \beta$ only. Scale bar, $100 \mu \mathrm{m}$

suggest that Bim might be an upstream regulator of Bax activation in oligomeric $\mathrm{A} \beta$-induced neurotoxicity and the pathological role of Bim and Bax in neuronal cell loss in AD.

However, it remains unknown how oligomeric $A \beta$ activates Bim and consequent neuronal cell death. Although future study will be required to determine the mechanism, one potential pathway might be c-Jun N-terminal kinase (JNK)dependent phosphorylation, as JNK-mediated phosphorylation promotes Bax-dependent apoptosis. ${ }^{28}$ As the activation of JNK by $\mathrm{A} \beta$ has been shown ${ }^{29}$ and the active form of JNK has been reported to be increased in vulnerable neurons in $A D,{ }^{30}$ it is plausible that the activation of JNK and subsequent activation of Bim/Bax-mediated apoptosis pathway might be the mechanism causing neuronal cell death in oligomeric $A \beta$ treated neurons and AD. Alternately, cyclin-dependent kinase 4 (Cdk4) has been suggested as an activator of Bim. Induction of Bim in nerve growth factor-deprived neuronal cells requires active Cdk4 and consequent reactivation of a series of genes suppressed by E2F. ${ }^{31}$ Among the reactivated genes, members of the myb transcription factor family, especially c-myb, seem to have a role in the activation of Bim. In previous studies, the inhibition of $\mathrm{Cdk}$ by various experimental approaches (i.e., chemical inhibitors, dominant-negative constructs, small interfering RNA) provide further evidence for the role of Cdk4 in the induction of Bim and neuronal cell death evoked by $A \beta .^{13,15,32}$ Given that the elevated expression of cell cycle-related proteins including $\mathrm{Cdk} 4$ is evident in the vulnerable neurons in $A D^{33-35}$ and $A \beta$-treated neuronal cells, ${ }^{32,36}$ an abortive reentry into the cell cycle might induce neuronal cell death by upregulating Bim/Bax apoptotic pathway. Supporting the causal role of cell cycle reentry in neuronal cell death, we previously found that dysregulation of cell cycle reentry results in neurodegeneration in vivo. ${ }^{37}$

Although we did not examine mRNA level of Bim and its posttranslational change, a previous report demonstrated that fibrillar $\mathrm{A} \beta$ increases the level of Bim mRNA and protein. ${ }^{13}$ Thus, the increase of Bim expression by $A \beta$ is likely mediated by transcriptional regulation. However, the increased translational modification such as phosphorylation of Bim might also be the reason for the increase of band intensity in our western blot data (Figure 2a). In fact, the western blot bands for upregulated Bim have a slightly higher molecular weight and this change may come from the phosphorylation of Bim, as Bim is known to be phosphorylated by several kinases. Cdk1/ Cyclin B1 is one of the kinases to phosphorylate Bim. ${ }^{38}$ Interestingly, in our recent study (manuscript in preparation), we found that $A \beta$ induced abnormal cell cycle upregulation as well as Cdk's activation and these events may have a role in posttranslational modification of Bim as seen in this study. Furthermore, the phosphorylation of Bim has been suggested to regulate Bax-dependent cell death. ${ }^{28}$ Therefore, the modification may regulate the apoptotic activity in our model. In future study, we will pursue the link between Cdk and Bim in $\mathrm{A} \beta$ neurotoxicity.

The present study showing Bax activation by oligomeric $A \beta$ and the resistance of $b a x^{-/-}$neurons to oligomeric $\mathrm{A} \beta$ cell death suggest that $\mathrm{Bax}$ is a key mediator of oligomeric $\mathrm{A} \beta$ toxicity, and therefore BIP's protective effects against oligomeric $\mathrm{A} \beta$ can be translated as the result of Bax inhibition. BIP was developed as a Bax-inhibiting peptide, however, as usual in any type of drug, we cannot entirely exclude the possibility that BIP has unexpected target(s) in the cell, which can regulate cellular response to oligomeric $A \beta$. The future study developing therapeutics based on BIP will need further careful examination of the possibilities of the existence of the target(s) of BIP in addition to Bax.

In conclusion, in this study, we found that $\mathrm{bax}^{-/-}$mice are resistant to oligomeric $\mathrm{A} \beta$-induced neuronal cell death, suggesting the essential role of Bax in neurotoxicity of oligomeric $\mathrm{A} \beta$. Furthermore, we show for the first time that BIP application prevents oligomeric $\mathrm{A} \beta$-induced neuronal cell death, suggesting that BIP and its mimetics may be utilized to mitigate the progress of $A D$ by rescuing neurons from Baxinduced cell death. Our study also suggests that oligomeric A $\beta$ regulates the activity of $\mathrm{Bim}, \mathrm{Bcl}-2$ and $\mathrm{Bax}$ in neurons. Taken all together, it is highly likely that the activation of Bax by the regulation of Bim and $\mathrm{Bcl}-2$ family is crucial for oligomeric $\mathrm{A} \beta$-induced neuronal cell death.

\section{Materials and Methods}

Materials. Anti- $\beta$-actin antibody was obtained from Millipore (Billerica, MA, USA) and anti-cleaved-caspase-3 antibody was obtained from Cell Signaling Technology (Danvers, MA, USA). A $\beta$ peptide $\left(\mathrm{A} \beta_{1-42}\right)$ and reverse control peptide $\left(A \beta_{42-1}\right)$ were purchased from AnaSpec (Fremont, CA, USA). PI and other chemicals were obtained from Sigma (St. Louis, MO, USA).

Preparation of oligomeric $\mathbf{A} \boldsymbol{\beta}$. Soluble oligomeric $A \beta$ was prepared from synthetic peptide according to a previous paper. ${ }^{39}$ Briefly, $1 \mathrm{mg}$ of $A \beta_{1-42}$ peptide was dissolved in $120 \mu \mathrm{l}$ of hexafluoroisopropanol for $60 \mathrm{~min}$ at room temperature, and placed back on ice for 5-10 min. After evaporation of hexafluoroisopropanol overnight in the hood at room temperature, the peptide was dissolved in $40 \mu \mathrm{l}$ of fresh anhydrous DMSO, and further diluted to $5 \mathrm{mM}$ stock solution. The stock peptide solution was then incubated for $24 \mathrm{~h}$ at $4^{\circ} \mathrm{C}$, and centrifuged at $14000 \times \mathrm{g}$ for $10 \mathrm{~min}$ at $4{ }^{\circ} \mathrm{C}$. Supernatant was used as oligomeric $A \beta$. Before we treated slice culture with oligomeric $\mathrm{A} \beta$, the oligomers were incubated at room temperature for $20 \mathrm{~h}$.

Mouse strains. Bax KO mice (strain name: $\left.B 6.129 \times 1-B a x t^{m 1 S j k} / J.\right)$ were purchased from The Jackson Laboratories (Bar Harbor, ME, USA). This Bax KO mouse has $\mathrm{C} 57 \mathrm{BL} / 6$ genetic background. Bax KO mice were crossed with wild- 
type C57BL/6 mice, and bax ${ }^{+/-}$mouse colony was generated. Bax KO as well as WT mice used for this study were generated by crossing $b x^{+1-}$ mice in our mouse colony. Each experiment used a set of Bax KO and WT mice obtained from the same parent to minimize variations caused by genetical differences among mice. bax ${ }^{-1-}$ mice were genotyped by PCR, as described previously. The primers for the wild-type and KO Bax alleles were $5^{\prime}$-GAGCTGATCAGAACCAT CATG-3' (sense) and $5^{\prime}$-CCGCTTCCATTGCTCAGCGG-3' (antisense). Conditions were set as follows: $94^{\circ} \mathrm{C}, 3 \mathrm{~min}(1 \mathrm{cycle}) ; 94^{\circ} \mathrm{C}, 30 \mathrm{~s}, 63^{\circ} \mathrm{C}, 1 \mathrm{~min}, 72^{\circ} \mathrm{C}$, $1 \mathrm{~min}$ ( $35 \mathrm{cycles}$ ); $72^{\circ} \mathrm{C}, 2 \mathrm{~min}$ ( 1 cycle). All protocols involving the use of mice were approved by the Institutional Animal Care and Use Committee of Case Western Reserve University.

Electron microscopy. $A \beta_{1-42}$ was adsorbed onto carbon films supported on Formvar (EMS, Hatfield, PA, USA) membrane-coated nickel grids. The excess buffered-protein solution was removed, and negatively stained with $2 \%$ uranyl acetate. Grids were then washed by touching the buffer and the excess buffer was immediately blotted using Whatman (Picataway, NJ, USA) filter paper. Grids were then air-dried and kept at room temperature. Negatively stained specimens were observed by a JEOL 1200EX electron microscope (JEOL, Tokyo, Japan) with $80 \mathrm{kV}$ of electron acceleration voltage.

Preparation of organotypic hippocampal slice cultures. Organotypic hippocampal slice cultures were prepared as described previously. ${ }^{40}$ Briefly, hippocampal slice cultures were prepared using 7-10-day-old mouse pups. Slices were cut at $400 \mu \mathrm{m}$ on a Mcllwain tissue chopper, transferred to Millicell membrane inserts $(0.4 \mu \mathrm{m}$; Millipore), and placed in 6 -well culture plates. The culture medium consisted of basal Eagle's medium with Earle's balanced salt solution, $20 \%$ heat-inactivated horse serum, enriched with $5.6 \mathrm{mM}$ glucose. The medium was changed every other day. The effect of oligomeric $A \beta(500 \mathrm{nM})$ was tested in the slices that had been maintained for 11-14 days in vitro. $A \beta$ oligomer or reversed sequence of $A \beta_{1-42}$ control peptide $\left(A \beta_{42-1}\right)$ was added to cultures in serum-free medium and, after the treatment, the hippocampal slices were rinsed twice in ice-cold phosphate-buffered saline (PBS), and then harvested by removing the Millicell membrane insert.

Assessment of neuronal cell death in organotypic hippocampal slice cultures. To determine neuronal cell death in the hippocampal slices, $\mathrm{PI}$ $(5 \mu \mathrm{g} / \mathrm{ml})$ was added to the slice culture medium. Images were acquired through an AxioCam camera on an Axiovert 200M microscope (Zeiss, Oberkochen, Germany). Fluorescent intensity was measured using Image $\mathrm{J}(\mathrm{NIH}$, Bethesda, MD, USA). Hematoxylin and eosin (H\&E) and Nissl staining was also performed for routine histochemical and morphological analyses.

Protein extraction and western blot analysis. After oligomeric $A \beta$ treatment, the slices were rinsed twice with ice-cold PBS and then lysed in ice-cold cell lysis buffer (Cell Signaling Technology) with protease and phosphatase inhibitor cocktail (Roche, Indianapolis, IN, USA). The protein concentration was determined by BCA assay (Pierce, Rockford, IL, USA). The extracted proteins were separated on 10 or $12 \%$ SDS-polyacrylamide gel and transferred onto polyvinylidene difluoride membranes. The blots were blocked with $10 \%$ non-fat milk in TBS-T for $1 \mathrm{~h}$ at room temperature, and then treated with primary antibodies diluted with $1 \%$ non-fat milk and incubated overnight at $4{ }^{\circ} \mathrm{C}$. The following antibodies were used for western blot analysis: anti-caspase-3 (1: 1000; Santa Cruz Biotechnology, Santa Cruz, CA, USA), anti-Bim (1:1000; Stressgen, Farmingdale, NY, USA), anti-Bcl-2 (1:1000; Stressgen) and 6A7 (conformational specific Bax antibody) (1:1000; BD Pharmingen, San Diego, CA, USA).

Intrahippocampal injection of oligomeric A $\boldsymbol{\beta}$. C57BL6/J mice (The Jackson Laboratories; 2-3-month-old) were anesthetized with pentobarbital and placed in a stereotaxic frame. Injection was made using a 10- $\mu$ microsyringe (Hamilton, Reno, NV, USA). A volume of $1 \mu$ l of oligomeric A $\beta$ dissolved at $50 \mu \mathrm{M}$ in PBS was injected into the left hippocampus. Control animals were prepared identically and injected with the same volume and concentration of $A \beta_{42-1}$ in PBS. Injections were made at stereotaxic coordinates from bregma; antereoposterior $(A P)=2.3 \mathrm{~mm}$, mediolateral $(\mathrm{ML})=2.5 \mathrm{~mm}$ and doroventral $(\mathrm{DV})=-2.5 \mathrm{~mm}$ according to a previous report. ${ }^{41}$ This corresponds to a site in the dorsal hippocampus in the apical dendritic zones of the CA1 region near the hippocampal fissure. Mice were killed 10 or 20 days after injection, brains dissected out, fixed in $10 \%$ buffered-formalin and paraffin-embedded. For brain tissue sections,
6- $\mu \mathrm{m}$-thick serial sections were cut, mounted onto slides and rehydrated according to standard protocols.

Immunocytochemistry. Cultured hippocampal slices were rinsed with icecold PBS once and fixed for $2 \mathrm{~h}$ with $4 \%$ paraformaldehayde in $0.1 \mathrm{M} \mathrm{PBS} .{ }^{42}$ After washing with PBS, sections were permeabilized overnight with PBS containing $0.2 \%$ Triton $X-100$. At the end of the permeabilization blocking solution, $10 \%$ normal goat serum in PBS was applied for $4 \mathrm{~h}$ at room temperature. After washing with PBS, primary antibody was added and incubated for $24-48 \mathrm{~h}$ at $4{ }^{\circ} \mathrm{C}$. After thorough washing of the sections in PBS, a secondary antibody labeled with either Alexa Fluor (Life Technologies, Grand Island, NY, USA) 488 or 568 (1:300) was added and incubated for $4 \mathrm{~h}$ at room temperature. All of the experiments contained at least one sample incubated without a primary antibody to exclude non-specific signal. Nuclei were visualized with DAPI. Images were acquired through an AxioCam camera on an Axiovert 200M microscope (Zeiss). Images were then analyzed with the Axiovision software (Zeiss).

TUNEL analysis. Detection of $3^{\prime}-\mathrm{OH}$ termini of DNA strand breaks was performed using in situ cell death detection kit (Roche). Briefly, the tissue sections were treated with proteinase $\mathrm{K}(20 \mu \mathrm{g} / \mathrm{ml}$ in $10 \mathrm{mmol} / \mathrm{I} \mathrm{Tris}-\mathrm{HCl}, \mathrm{pH} 7.4)$ for $30 \mathrm{~min}$ at $37^{\circ} \mathrm{C}$ after rehydration. After rinsing with PBS, TUNEL reaction mixture containing terminal deoxynucleotidyl transferase and fluorescence-labeled nucleotide was applied for $1 \mathrm{~h} 37^{\circ} \mathrm{C}$. The samples were then washed and mounted using Aquamount (Southern Biotech, Birmingham, AL, USA).

Statistical analysis. Data were expressed as the means \pm S.E.; the number of independent experiments is indicated in the corresponding figure legend. Differences between groups were examined for statistical significance using one-way analysis of variance with an unpaired Student's $t$-test. A $P$ value of $<0.05$ indicated a statistically significant difference.

\section{Conflict of Interest}

Dr. Xiongwei Zhu was a consultant for and received grant support from Medivation. Dr. Mark A Smith was a consultant for Anavex Life Sciences Corporation, Eisai, Medivation, Neurotez and Takeda Pharmaceuticals; owned stock options in Aria Neurosciences, Neurotez, Panacea and Voyager, and received lecture fees from GSK, Medivation and Pfizer.

Acknowledgements. We thank Dr. Hisashi Fujioka for electron microscopy analysis. This work was supported by the National Institutes of Health (AG028679 to HL; AG031903 and P30CA043702 to SM); the Alzheimer's Association (IIRG-11-173471 to HL).

1. Lambert MP, Barlow AK, Chromy BA, Edwards C, Freed R, Liosatos M et al. Diffusible, nonfibrillar ligands derived from Abeta1-42 are potent central nervous system neurotoxins. Proc Natl Acad Sci USA 1998; 95: 6448-6453.

2. Kudo W, Lee HP, Zou WQ, Wang X, Perry G, Zhu X et al. Cellular prion protein is essential for oligomeric amyloid-beta-induced neuronal cell death. Hum Mol Genet 2012; 21: 1138-1144.

3. De Felice FG, Velasco PT, Lambert MP, Viola K, Fernandez SJ, Ferreira ST et al. Abeta oligomers induce neuronal oxidative stress through an $\mathrm{N}$-methyl-D-aspartate receptor-dependent mechanism that is blocked by the Alzheimer drug memantine. J Biol Chem 2007; 282: 11590-11601.

4. Kitamura Y, Shimohama S, Kamoshima W, Ota T, Matsuoka Y, Nomura Y et al. Alteration of proteins regulating apoptosis, Bcl-2, Bcl-x, Bax, Bak, Bad, ICH-1 and CPP32, in Alzheimer's disease. Brain Res 1998; 780: 260-269.

5. Davies AM. The Bcl-2 family of proteins, and the regulation of neuronal survival. Trends Neurosci 1995; 18: 355-358.

6. Farrow SN, White JH, Martinou I, Raven T, Pun KT, Grinham CJ et al. Cloning of a bcl-2 homologue by interaction with adenovirus E1B 19K. Nature 1995; 374: 731-733.

7. Zornig M, Hueber A, Baum W, Evan G. Apoptosis regulators and their role in tumorigenesis. Biochim Biophys Acta 2001; 1551: F1-37.

8. Hsu YT, Youle RJ. Bax in murine thymus is a soluble monomeric protein that displays differential detergent-induced conformations. J Biol Chem 1998; 273: 10777-10783.

9. Nechushtan A, Smith CL, Hsu YT, Youle RJ. Conformation of the Bax C-terminus regulates subcellular location and cell death. EMBO J 1999; 18: 2330-2341. 
10. Gomez JA, Gama V, Yoshida T, Sun W, Hayes P, Leskov K et al. Bax-inhibiting peptides derived from Ku70 and cell-penetrating pentapeptides. Biochem Soc Trans 2007; 35(Pt 4): 797-801.

11. Yoshida T, Tomioka I, Nagahara T, Holyst T, Sawada M, Hayes P et al. Bax-inhibiting peptide derived from mouse and rat Ku70. Biochem Biophys Res Commun 2004; 321: 961-966.

12. Gomez JA, Chen J, Ngo J, Hajkova D, Yeh IJ, Gama V et al. Cell-penetrating pentapeptides (CPP5s): measurement of cell entry and protein-transduction activity Pharmaceuticals (Basel) 2010; 3: 3594-3613.

13. Biswas SC, Shi Y, Vonsattel JP, Leung CL, Troy CM, Greene LA. Bim is elevated in Alzheimer's disease neurons and is required for beta-amyloid-induced neuronal apoptosis. J Neurosci 2007; 27: 893-900.

14. Zhu X, Wang Y, Ogawa O, Lee HG, Raina AK, Siedlak SL et al. Neuroprotective properties of Bcl-w in Alzheimer disease. J Neurochem 2004; 89: 1233-1240.

15. Giovanni A, Keramaris E, Morris EJ, Hou ST, O'Hare M, Dyson N et al. E2F1 mediates death of B-amyloid-treated cortical neurons in a manner independent of $\mathrm{p} 53$ and dependent on Bax and caspase 3. J Biol Chem 2000; 275: 11553-11560.

16. Lauren J, Gimbel DA, Nygaard HB, Gilbert JW, Strittmatter SM. Cellular prion protein mediates impairment of synaptic plasticity by amyloid-beta oligomers. Nature 2009; 457 : 1128-1132.

17. Li Y, Yokota T, Gama V, Yoshida T, Gomez JA, Ishikawa K et al. Bax-inhibiting peptide protects cells from polyglutamine toxicity caused by Ku70 acetylation. Cell Death Differ 2007; 14: 2058-2067.

18. Gross A, McDonnell JM, Korsmeyer SJ. BCL-2 family members and the mitochondria in apoptosis. Genes Dev 1999; 13: 1899-1911.

19. Putcha GV, Deshmukh M, Johnson EM Jr. BAX translocation is a critical event in neuronal apoptosis: regulation by neuroprotectants, BCL-2, and caspases. J Neurosci 1999; 19: 7476-7485.

20. Eskes R, Desagher S, Antonsson B, Martinou JC. Bid induces the oligomerization and insertion of Bax into the outer mitochondrial membrane. Mol Cell Biol 2000; 20: 929-935.

21. Edlich F, Banerjee S, Suzuki M, Cleland MM, Arnoult D, Wang C et al. Bcl-x(L) retrotranslocates Bax from the mitochondria into the cytosol. Cell 2011; 145: 104-116.

22. Tait SW, Green DR. Mitochondria and cell death: outer membrane permeabilization and beyond. Nat Rev Mol Cell Biol 2010; 11: 621-632.

23. Letai A, Bassik MC, Walensky LD, Sorcinelli MD, Weiler S, Korsmeyer SJ. Distinct BH3 domains either sensitize or activate mitochondrial apoptosis, serving as prototype cancer therapeutics. Cancer Cell 2002; 2: 183-192.

24. Gavathiotis E, Suzuki M, Davis ML, Pitter K, Bird GH, Katz SG et al. BAX activation is initiated at a novel interaction site. Nature 2008; 455: 1076-1081.

25. Green DR, Chipuk JE. Apoptosis: stabbed in the BAX. Nature 2008; 455: 1047-1049.

26. Whitfield J, Neame SJ, Paquet L, Bernard O, Ham J. Dominant-negative c-Jun promotes neuronal survival by reducing BIM expression and inhibiting mitochondrial cytochrome $\mathrm{C}$ release. Neuron 2001; 29: 629-643.

27. Czabotar PE, Colman PM, Huang DC. Bax activation by Bim? Cell Death Differ 2009; 16 : 1187-1191.

28. Putcha GV, Le S, Frank S, Besirli CG, Clark K, Chu B et al. JNK-mediated BIM phosphorylation potentiates BAX-dependent apoptosis. Neuron 2003; 38: 899-914.
29. Ma QL, Yang F, Rosario ER, Ubeda OJ, Beech W, Gant DJ et al. Beta-amyloid oligomers induce phosphorylation of tau and inactivation of insulin receptor substrate via c-Jun $\mathrm{N}$-terminal kinase signaling: suppression by omega-3 fatty acids and curcumin. J Neurosci 2009; 29: 9078-9089.

30. Zhu X, Ogawa O, Wang Y, Perry G, Smithzzz MA. JKK1, an upstream activator of JNK/SAPK, is activated in Alzheimer's disease. J Neurochem 2003; 85: 87-93.

31. Biswas SC, Liu DX, Greene LA. Bim is a direct target of a neuronal E2F-dependent apoptotic pathway. J Neurosci 2005; 25: 8349-8358.

32. Giovanni A, Wirtz-Brugger F, Keramaris E, Slack R, Park DS. Involvement of cell cycle elements, cyclin-dependent kinases, pRb, and E2F x DP, in B-amyloid-induced neuronal death. J Biol Chem 1999; 274: 19011-19016.

33. Webber KM, Raina AK, Marlatt MW, Zhu X, Prat MI, Morelli $L$ et al. The cell cycle in Alzheimer disease: a unique target for neuropharmacology. Mech Ageing Dev 2005; 126 : 1019-1025.

34. Zhu X, McShea A, Harris PL, Raina AK, Castellani RJ, Funk JO et al. Elevated expression of a regulator of the G2/M phase of the cell cycle, neuronal CIP-1-associated regulator of cyclin B, in Alzheimer's disease. J Neurosci Res 2004; 75: 698-703.

35. Bajic VP, Su B, Lee HG, Kudo W, Siedlak SL, Zivkovic $L$ et al. Mislocalization of CDK11/PITSLRE, a regulator of the G2/M phase of the cell cycle, in Alzheimer disease. Cell Mol Biol Lett 2011; 16: 359-372.

36. Varvel NH, Bhaskar K, Patil AR, Pimplikar SW, Herrup K, Lamb BT. Abeta oligomers induce neuronal cell cycle events in Alzheimer's disease. J Neurosci 2008 28: $10786-10793$.

37. Lee HG, Casadesus G, Nunomura A, Zhu X, Castellani RJ, Richardson SL et al. The neuronal expression of MYC causes a neurodegenerative phenotype in a novel transgenic mouse. Am J Pathol 2009; 174: 891-897.

38. Mac Fhearraigh S, Mc Gee MM. Cyclin B1 interacts with the BH3-only protein Bim and mediates its phosphorylation by Cdk1 during mitosis. Cell Cycle 2011; 10: 3886-3896.

39. Klein WL. Abeta toxicity in Alzheimer's disease: globular oligomers (ADDLs) as new vaccine and drug targets. Neurochem Int 2002; 41: 345-352.

40. Gogolla N, Galimberti I, DePaola V, Caroni P. Preparation of organotypic hippocampal slice cultures for long-term live imaging. Nat Protoc 2006; 1: 1165-1171.

41. Clavaguera F, Bolmont T, Crowther RA, Abramowski D, Frank S, Probst A et al. Transmission and spreading of tauopathy in transgenic mouse brain. Nat Cell Biol 2009; 11: 909-913.

42. Gogolla N, Galimberti I, DePaola V, Caroni P. Staining protocol for organotypic hippocampal slice cultures. Nat Protoc 2006; 1: 2452-2456.

Cell Death and Disease is an open-access journal published by Nature Publishing Group. This work is licensed under the Creative Commons Attribution-NonCommercial-No Derivative Works 3.0 Unported License. To view a copy of this license, visit http://creativecommons.org/licenses/by-nc-nd/3.0/ 